\title{
Language as a Symbol of Group Membership
}

\author{
Narjes Ghafournia ${ }^{1}$ \\ ${ }^{1}$ Department of English, Neyshabur Branch, Islamic Azad University, Neyshabur, Iran \\ Correspondence: Narjes Ghafournia, Department of English, Neyshabur Branch, Islamic Azad University, \\ Neyshabur, Iran. Tel: 98-915-313-0060. E-mail: narjesghafournia@yahoo.com; na.ghafournia@gmail.com
}

Received: July 30, 2014 Accepted: November 5, 2014 Online Published: February 12, 2015

doi:10.5539/ass.v11n5p19 URL: http://dx.doi.org/10.5539/ass.v11n5p19

\begin{abstract}
Whenever we speak in a particular language variety rather than another, we display an affinity with one social group distancing ourselves from other social groups. The identity-marking function of speech is as important as the communicative one. The type of language variety, people use, makes a considerable contribution to shape their social identities. This means that the people with high social or political status should often carefully control their language styles in order to exert profound influence on people's attitudes to meet desired expectations. In fact, social class-based language differences may have more important social implications than regional variations. In many class-conscious societies, particular varieties associated with lower social classes, may be greatly stigmatized by the members of the society. Hence, the speakers of less prestigious varieties may often lose many educational and occupational opportunities unfairly. However, a language variety in linguistic term is more expressive, logical, regular, and correct than social varieties. Therefore, making any valid judgment on the superiority or inferiority of a particular language variety is concerned with social and political affairs and does not have any linguistic merits. The article also discusses the relation between language variety and cognitive ability of language users based on Bernstein's theory and the critics.
\end{abstract}

Keywords: social class, prestigious language, standard language, elaborated code, restricted code

\section{Introduction}

Although it is a widely held belief that language variation is heavily dependent on regional variation, it has been recognized that people within the same region may differ in the language patterns they use with regard to their social class or simply the social group to which they belong. In other words, a speaker of a particular language may be broadly similar in the language patterns to the people from the same social group in different geographical areas, but different in the language patterns of varying social groups in the same geographical area in a society. To put it simply, while a regional dialect provides a geographical answer to the question of "Where are you from?" a social dialect provides an answer to different questions of "Who are you?", "What are you?", "What is your social role?", and "What kind of social group do you belong to?" (Crystal, 2004, 2010). Thus, an individual's real social identity is heavily dependent on the language he/she uses as a chief signal of both permanent and transient aspects of social identity.

In fact, social class-based language differences may have greater social implications than regional variations. For example, particular language varieties, used by the members of lower social classes may be severely stigmatized and subject to scorn and negative social sanction in some class-conscious societies. In some societies, there may be great discrimination against lower social varieties in educational and occupational settings. In other words, the members of lower social classes usually lose many academic and occupational opportunities. In contrast, such great discrimination and stigmatization are less evident in the case of different regional dialects. In other words, different regional dialects may be considered interesting, unusual, quaint, and to some extent charming. In contrast, no sever social and public discrimination usually exists against regional variations (Fasold \& Connor-Linton, 2006).

In general, all countries display some extent of social stratification, or class-consciousness. However, some countries have been more specifically defined as class boundaries than others have. Such countries often show high prejudice for and against some identifiable features of special class dialects. Hence, having a brief review of some class-conscious countries and their effect on language use is of related importance. 


\section{The Use of Language in Class-Conscious Societies}

A good example of the countries that are linguistically much more class conscious than other countries is Great Britain, where English is used as the first language. In other words, one prominent characteristic of highly hierarchical social structure of a country like Great Britain is that social class takes precedence over geography as a determinant of speech. In this society, the majority of the people who have higher educational backgrounds would like to attain powerful and prestigious positions and rarely show any sign of regional dialects in their speech.

Other examples of highly social class-conscious societies, where social dialects are of particular concern, are India and Indonesia. In these societies, social divisions are very clear - cut, which are reflected considerably through speech differences. In India, for example, there are quite clear linguistic differences between the speech of Brahmins and non-Brahmin due to social differences. One clear example, depicting the great differences between Brahmin and non- Brahmin speech is the pronunciation of the word 'milk'. For non-Brahmin group, the word is pronounced 'aalu' whereas Brahmins pronounce it 'haalu' (Holmes, 1992).

Language variation with regard to social class differentiation is also significantly seen in Australian English with hardly grammatical distinctiveness, but a great deal of phonological distinctive features. In fact, because of great language variation in Australia, mostly related to social factors, Mitchell and Delbridge (1960) classified Australian language into three groups of cultivated, broad, and general accents. The classification is still at work with little controversy in this society due to great language variation as the result of social class differences. Based on the classification, cultivated language is used by 10 percent of the population, on which Received Pronunciation exerts a considerable influence. This accent is indeed very close to the accent of the educated people in the Southern British with just a hint of the Australian origin. However, at the opposite extreme, broad accent is used by about 30 percent of the population, mostly identified by the notion of Australian twang. Finally, there is a general Australian accent in between, used by most of the ordinary population (Perelstsvaig, 2012).

Therefore, due to great effect of social class on the type of speech variety, in half of the twentieth century, many sociolinguists began to turn their focus toward social class-based language variation rather than merely focusing on regional variation. Having a brief elaboration on some of the relevant classical studies in this area is undoubtedly very insightful.

\section{Empirical Backgrounds}

One of the most famous and primary debates on the type of English language use and social class took place in 1950s, following the publication of an article on a particular issue by a British linguist, Alan Ross. In this article, Rose pointed to the differences between upper class and other groups of people in the use of ' $U$ ' in terms of distinctive pronunciation use in different vocabularies and written language conventions. Although the article was very impressionistic, it was very perceptive and provoked an enormous public reaction (Crystal, 2004, 2010).

Another significant pioneering study, which proved the patterned nature of dialect variety concerning speakers' social classes was carried out by William Labov (1966), who conducted a comprehensive sociolinguistic study on the language of the Lower East side of New York City. Labov's study has been of particular significance among different relevant studies, investigating the effect of social class on the type of language use. Therefore, due to the great prominence of the study, a brief elaboration on it seems necessary and influential.

\subsection{Labov's Classical Study}

In his study, Labov conducted informal sociolinguistic interviews with hundreds of native speakers, who belonged to different social class groups. He examined how frequently the people used linguistic features, typical of New York City dialect. In fact, Labov's interview was constructed in the way that it elicited the speech of different levels of formality. Therefore, he could examine different usage levels, based on the type of language style. His analysis showed a quite regular speech patterns, regarding the social class and style of language use. His findings are illustrated in Figure 1 and Figure 2.

Figure 1 shows the patterning of a prestigious language use feature, regarding r-pronunciation, versus less prestigious or stigmatized r-lessness. In comparison, Figure 2 shows the patterning of a stigmatized feature, or the pronunciation of [ $\theta$ ], as occurs in the word with [wIt] or the word thing [tIn]. In both cases, the styles range from very informal (style A, casual speech) to very formal ones (style D, lists of isolated words). Minimal pairs (style D) are considered even more formal and self-conscious among other styles, used in other stages of the study. In this stage of the study, the interviewees had to read pairs of words that only differed in a single sound 
in Standard American English. However, the words might sound the same in r-less New York City speech. Good examples of such words were source and guard, which in r-less speech variety were considered as sauce or god.

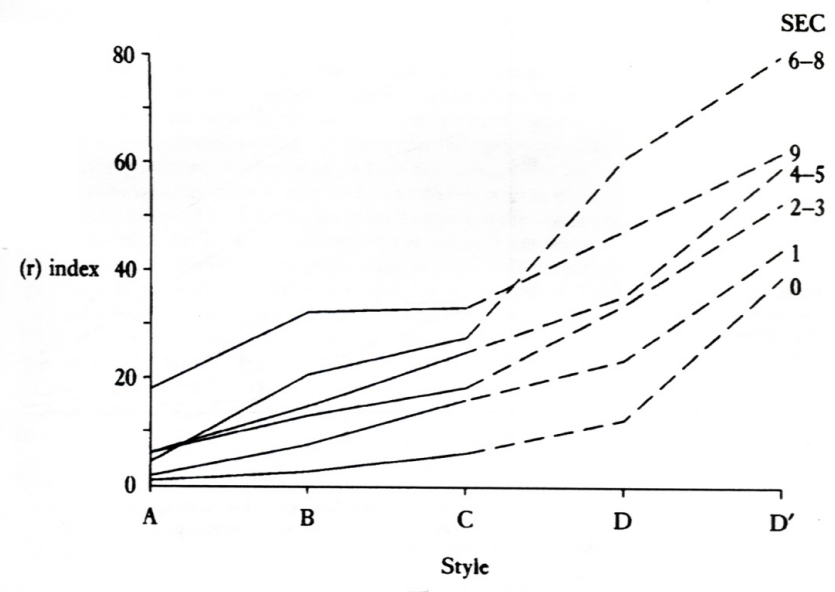

SEC scale: 0-1, lower class; $2-3$, working class; 4-5, 6-8, lower middle class; 9, upper middle class. A, casual speech; B, careful speech; C, reading style;

$\mathrm{D}$, word lists; $\mathrm{D}^{\prime}$, minimal pairs.

Figure 1. The regular patterning of a prestigious dialect feature according to social class and speech style: $r$ in New York City English (Labov, 1972)

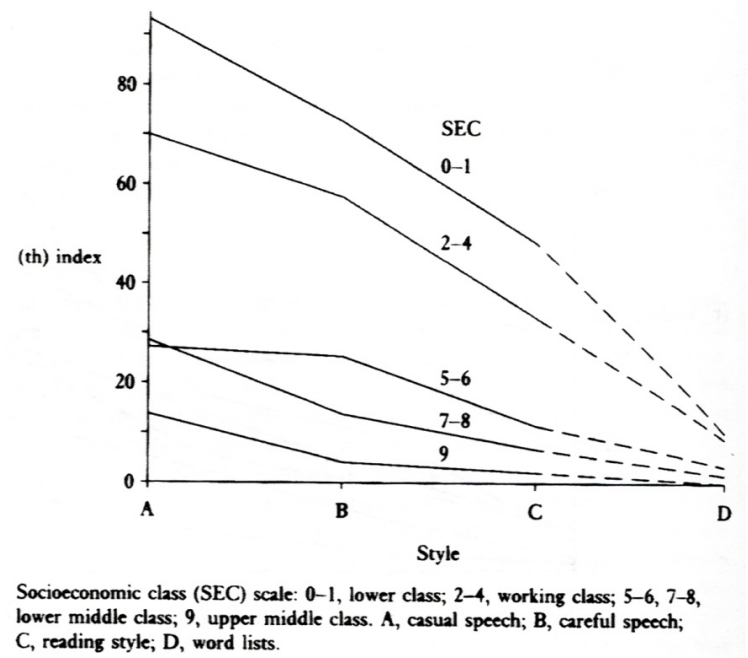

Figure 2. The regular pattering of a stigmatized dialect feature by social class and speech style: [t] for [ $\theta$ ] (e.g., writ for 'with') in New York City English (Labov, 1972)

Careful analysis of Figure 1 shows that speakers in lower socioeconomic class used prestigious features less frequently, whereas the speakers in progressively higher classes used prestigious language use more frequently. In addition, all class groups applied the prestigious features more frequently when speakers moved from less self-conscious speech styles on the left hand side of the graph to more self-conscious styles on the right. The only exception, as Labov mentioned, was reflected in the lower-middle class, who used the prestigious pronunciation more frequently than the speakers of the highest social class groups in the two most formal styles (word list and minimal pair styles). Labov tried to account for this exception through considering the use of hypercorrection by the lower class, who desired for upward mobility, revealed in the more conscious use of language.

Careful analysis of Figure 2 also depicts that lower class speakers used stigmatized features more frequently than did higher class individuals. In addition, the speakers in all class groups used less prestigious and stigmatized 
linguistic features less and less, as they moved from casual or unself-conscious speech to conscious situations, where they were greatly conscious of their correct or formal use of language.

In general, Labov's findings had much significant influence on the sociolinguists, encouraging them to turn their attention toward social class- based language variation in different societies. Therefore, many researchers began to explore the significant correlation between social class and speech variation in both English-speaking and non-English-speaking areas in the world. Among the most influential studies, exploring the significant correlation in some English speaking areas, systematic studies accomplished by Shuy et al. (1967) in Detroit, Michingan; Trudgil, (1974) in Norwich, England; and Maculay (1976) in Glasgow, Scotland are of particular importance. The same correlation was also found in other non-English speaking areas in the world by other researchers, the most famous of which are the studies conducted by Sankoff and Cedergren (1971), Sankoff and Vincent (1977) in the French use of the people in Monterial, and the study by Cedergren (1973) about the use of Spanish in Panama.

The influence of social class variation on the type of language use is not limited to particular large societies, and even is of significance in small villages. For example, Richford (1986) found that in the village of Cone Walk and Guyana, there was a sharp division of two social class groups of Estate Class, who worked on the sugar estates as unskilled laborers, and the Non- Estate Class, who worked as foremen, drivers, and skilled tradesmen. Richford's investigation showed that each social group preferred to use quite different language norms. For example, Non-Estate Class showed great inclination and interest in using more prestigious and Standard English norms, whereas Estate Class mostly used less prestigious language.

\section{Social Class and Choice of Language Variety by Non-human Species}

The significance of social identifying- function of language is so great that it has been even demonstrated to be shared with some non-human species. In other words, although animals do not use language, in the sense of human language, they use dialects to help them mark their social divisions (Crystal, 2014). For example, white crowned sparrows use clear and buzzing variety of their basic bird songs. This variety is only applied by the groups of the birds in the north and south part of Point Reys in Marin County in California (Baker \& Cunningham, 1985). The findings of another study by Rendall and Whitehead (2001) also revealed that Humpback whales similarly have distinct versions of their underwater songs, associated with different pods.

Therefore, by a short review over the mentioned studies, it can be inferred that social identity function of language is of significance as it is even shared with non-human species too.

\section{The Relation between Social Class and Language Leaning Ability}

One of the other relevant controversial issues is related to the relation between different social classes and the individuals' learning abilities in their use of language. In fact, this was one of the most controversial issues began to be widely discussed in the 1960s as the result of Bernstein's work on the link between social class, language and education, which led him to make a distinction between two general linguistic codes of restricted and elaborated (Bernstein, 1961).

Based on Bernstein's theory, a restricted code is described as short simple grammatical sentences, full of reduced vocabularies, question tags, and pronouns instead of nouns. In fact, it is greatly context-bound (Richard \& Schmidt, 2010). This type of language use arises where meanings are particular and embedded in a local context. In restricted language, the need to make meaning specific and explicit is reduced through shared understanding, values, and identification between speakers and addressees. In contrast, elaborated code consists of longer grammatical complex structures, full of adjectives and nouns instead of pronouns, which make this kind of language use more context-independent than retracted code (Richard \& Schmidt, 2010). In comparison, elaborated code is more explicit. The speakers who use elaborated language do not assume the same degree of shared attitudes and expectations on the part of the addressee. According to Bernstein's theory, elaborated code is needed to be used at school, where it is important for both teachers and students to be able to speak explicitly and clearly. However, in reality, most of children are unequal in their knowledge of elaborated language due to different social classes and cultural backgrounds. While middle class children have access to both language codes, lower class children are more likely to be initially limited to restricted language. They often experience major difficulties in acquiring elaborated code, required by school at later stages. Thus, lower class children are less able to understand the meanings and pedagogical practices, regulated by elaborated code at school (Hudson, 1996). Bernstein also believed that not only using different codes have educational consequences but also it leads to cognitive differences between members of different social class. In other words, children who have adopted the use of restricted code do not develop their full cognitive abilities. Therefore, in this respect, Bernstein's view is similar to Linguistic Relativity Hypothesis or Whorfian Hypothesis in that different forms of language lead to 
different ways of thinking. The complexities of Bernstein's theory were sometimes reduced to the proposition that middle-class children are able to think abstractly, but working class children are not. This difference can be attributed to the differences in the children's linguistic resources (Crystal, 2013).

Bernstein's theory has been strongly criticized and discredited among many sociolinguists for the lack of empirical evidence of its key assumptions such as the essence of explicitness at school and inability of some children to talk explicitly (e.g., Edwards, 1994; Labov, 1972; Lawton, 1968; Maclure, 1994; Wells, 1981). Among many critics, Labov is one of the strongest ones, who opposed Bernstein's theory because of showing great bias against working- class behavior and superiority of middle - class language. Labov, on the other hand, believed that language of working class was not restricted, and different alternative forms and elaborated code were not superior. In addition, Labov strongly criticized Bernstein's view about limited abilities of lower-class speakers in abstract reasoning due to using non-standard languages or the restricted codes through showing the great ability of these people to think abstractly and handle complex abstract concepts in restricted code.

In sum, although using different language varieties have important implications in education, and the students using restricted varieties may not reach their full potentials if the educational system is geared towards a standard and elaborated variety, using restricted codes cannot make a significant differentiation between different social class people concerning their cognitive abilities. Perhaps, one important reason for poor performance of lower class students is their deprivation of equal educational opportunities in that most of educational systems do not take into account students' vernacular dialects or restricted codes, to which these children have been accustomed from the beginning.

In general, elaboration on the effect of social class on language use is evidently not a simple matter because many other intervening factors should be carefully taken into consideration. Factors such as context of language use, family structure, social background, social and emotional attitudes, cultural, and religious points, social settings, educational and occupational systems, age, and gender should not be taken for granted while debating the issue.

Although the significant correlation between social class and language use has been supported by many researches, it seems that some sociolinguists reluctantly accept it and regard people's patterns of conduct or social network more responsible for language variation rather than membership in a particular social group. For example, Milroy and Milory (1978) and Milory (1987), in a ground breaking sociolinguistic study of Belfast in the Northern Ireland, showed that patterns of variation and change correlated quite well with dense and multiplex social networks of the speakers. It was particularly found that people who belonged to dense, multiplex networks tended to maintain local, vernacular speech features and resisted linguistic innovations from outside the local area. Conversely, those with loose social ties were much more open to language change. The findings are of significance because they have illuminated that the large-scale patterns of language variation are not only often found across social class groups, but also other important social factors considerably contribute to language variation. Therefore, although social class has been the primary social variable in many sociolinguistic studies, sociolinguists are well aware that some social groups are not class-differentiated, but rather linguisticdifferentiated. Clearly, within tightly structured, relatively homogeneous social clusters such as neighborhoods, parishes, institutions, individuals further demarcate themselves by patterns of language variation. These micro-level social clusters are called networks explaining various kinds of individual behaviors, which cannot be explained in terms of corporate group membership (Milory, 1980).

In addition, although in many class-conscious societies, language acts as a strong weapon, contributing significantly to maintain the gap between higher classes and lower classes, this gap can be filled if educational system enshrines non-standard varieties through focusing on the language of lower class as well (Chamber, 2003). Furthermore, the linguistic differentiation, imposed by higher classes to mark their position at the top of hierarchy, is only sustained by higher classes while other lower classes play key roles in sustaining linguistic differentiation albeit covertly or in a simpler word, by using covert prestige (Holmes, 1992).

In sum, as Labov (1970) believed, although social factors significantly influence the choice of language, the great overlap between social values and language structures should not be underestimated. In fact, social values are in close correspondence with language surface structure, which is subject to great variation. Speakers do not readily accept the fact that two different language structures actually mean the same, and there is a strong tendency between people of different social classes to attribute different meanings to them. However, as far as the synchronic aspect of language structure is concerned, it would be an error to put much emphasis on social factors. For example, generative grammarians have made great progress in working out the invariant relations between language structures in spite of neglecting the social context of language. For instance, Chomsky has 
never appeared to find much value in the use of language concerning the social class. In Chomsky's opinion, the differences between the varieties of a language are performance-based and have little value to offer for a better understanding of the real nature of language.

In addition, some sociolinguists criticize social class-based studies such as Labov's study due to describing group behavior rather than individual linguistic competence. In fact, language variation is not haphazard; instead, it is systematic and is partly the result of many social and linguistic factors. It is evident that sometimes consciously or unconsciously, certain variables are considered more prestigious than others in a society. Therefore, people are able to change their speech in different circumstances systematically (Wardhaugh, 1990). Consequently, it seems clear that major advances toward understanding the mechanism of linguistic change is not possible without serious study of social factors, which motivate linguistic evolution (Labov, 1970).

\section{Conclusions}

Sociolinguists are not only interested in investigating the regional or geographical background of language users, or answer the question of "Where are you from?", but also show particular interest in focusing on the social identity or the question of "Who are you?", with regard to individuals' speech. The latter question is more complex and multi-faceted. Hence, finding an acceptable answer to it seems rather difficult. In fact, people achieve varying social status as they participate in varying social structures; therefore, they belong to many social groups and perform a large variety of social roles. Consequently, finding a single clear classification, which defines exactly a person's social identity based on the language use is very difficult. In addition, because of the inevitable interaction of many social and regional factors, making an exact and straightforward statement about language variation in terms of social class differences seems nearly impossible. In fact, within the field of sociolinguistics, the theoretical basis of linguistic diversity concerned with social identity is one of the most controversial issues due to the great intervention of other social and cultural factors. Fortunately, in spite of many complexities, sociolinguists have made great progress in determining the significant correlations between social class background and language use, some of which were discussed in this article.

\section{References}

Baker, M. C., \& Cunningham, M. A. (1985). The biology of bird. Song dialects. Behavioral and Brain Sciences, 8, 85-99. http://dx.doi.org/10.1017/s0140525x00019750

Bernstein, B. (1961). Social structure, language and learning. Educational research (London), 3(3), $163-176$. http://dx.doi.org/10.1080/0013188610030301

Bernstein, B. (Ed). (1973). Class, codes and control, volume II: Empirical studies. London: Routledge and Kegan Paul. http://dx.doi.org/10.1017/s0047404500004504

Cedergren, H. (1973). The interplay of social and linguistic factors in panama (PhD dissertation). Cornell University.

Chamber, J. K. (2003). Sociolinguistic theory (2nd ed.). Great Britain: Blackwell Publishing.

Crystal, D. (2004). The Cambridge encyclopedia of the English language (2nd ed.). Cambridge. Cambridge University Press.

Crystal, D. (2010) The Cambridge encyclopedia of language (10th ed.). Cambridge. Cambridge University Press.

Crystal, D. (2013). Clinical linguistics (disorders of human communications). Springer: Verlay Wien GmbH.

Crystal, D. (2014). An introduction to language (9th ed.). United States of America: Senior Publisher.

Edwards, J. (1994). Educational failure. ELL.

Fasold, R. W., \& Connor-Linton, J. (Eds.). (2006). An introduction to language and linguistics. Cambridge: Cambridge University Press.

Holmes, J. (1992). An introduction to sociolinguistics. United States: Longman.

Hudson, J. (1996). Trends in Multi-authored Papers in Economics. Journal of Economic Perspectives, 10(3), 153-158. http://dx.doi.org/10.1257/jep.10.3.153

Hudson, R. A. (1996). Sociolinguistics (2nd ed.). Cambridge: Cambridge University Press.

Labov, W. (1966). The Social stratification of English in New York City. Washington, Dc: Center for Applied Linguistics.

Labov, W. (1970). The study of language in its social context. Stadium Generate, 23, 30-87. 
http://dx.doi.org/10.1515/zrs.2010.005

Labov, W. (1972). Sociolinguistic patterns. Oxford: Blackwell. http://dx.doi.org/10.1017/s0047404500004528

Lawton, D. (1986). Social class. Language and education. London: Routledge and Kegan Paul. http://dx.doi.org/10.1177/030639686901000334

Maclure, M. (1994). Home language and school language ELL, 159, 3-5. http://dx.doi.org/10.1017/cbo9780511620737.007

Maculay, R. K. (1976). Social class and language in Glasgow. Language in Society, 5, 173-188. http://dx.doi.org/10.1017/s0047404500007016

Milroy, L. (1980). Language and social networks. Oxford: Basil Blackuell. http://dx.doi.org/10.1017/s0022226700007362

Milroy, L. (1987). Observing and analyzing natural language: A critical account of sociolinguistic method. Oxford: Basil Blakwell. http://dx.doi.org/10.2307/2073872

Milroy. J., \& Milroy, L. (1978). In P. Trudgill (Ed.), Belfast: Change and Variation in an urban vernacular. Sociolinguistic patterns in British English (pp. 19-36). London: Edward Arnold.

Mitchell, A. G., \& Delbridge, A. (1965). The pronunciation of English in Australia. Sydney: Angus and Roberstson. http://dx.doi.org/10.2307/20630899

Perelstsvaig, A. (2012). Languages on the world. Cambridge: Cambridge University Press.

Rendall, L., \& Whiteheas, H. (2001). Culture in whales and dolphins, Behavioral and Brain Sciences, 24, 309-323. http://dx.doi.org/10.1017/s0140525x0100396x

Richard, J. C., \& Schmidt, R. (2010). Longman dictionary of language teaching and applied linguistics (4th ed.) England: Longman.

Richford, J. R. (1986). The need for new approaches to social class analysis in sociolinguistics. Language and Communication, 6(3). http://dx.doi.org/10.1016/0271-5309(86)90024-8

Ross, A. S. C. (1956). U and non-U: an essay in sociological linguistics. In N. Mitford (Ed.), Nobleness Oblige. London: Hamish Hamilton.

Sankoff, G., \& Cedergren, H. (1977). Some results of a sociolinguistic study of Montreal French. In R. Darnell (Ed.), Lingusitic diversity in Canadian Society (p. 61, p. 87), Edmonton: Linguistic Research, Inc.

Sankoff, G., \& Vincent, D. (1977). Lemploi product if du Ne dans Le Francais parle Montreal. Le Fracais Moderne, 45, 243-256. http://dx.doi.org/10.3406/lfr.1977.4818

Shuy, R. W., Wolfram, W., \& Riley. W. K. (1967). Linguistic correlates of social stratification in Detroit speech. USOE Final Report, 6. http://dx.doi.org/10.2307/3087867

Trudgil, P. (1974). The social differentiation of English in Norwich. Cambridge University Press. http://dx.doi.org/10.1017/s0022226700004631

Wardhaugh, R. (1990). An introduction to sociolinguistics. Great Britain: Basil Blackwell. http://dx.doi.org/10.1177/144078338702300217

Wells. J. (1981). Learning through interaction. The study of language development. Cambridge: Cambridge university press. http://dx.doi.org/10.1017/s0305000900005456

\section{Copyrights}

Copyright for this article is retained by the author(s), with first publication rights granted to the journal.

This is an open-access article distributed under the terms and conditions of the Creative Commons Attribution license (http://creativecommons.org/licenses/by/3.0/). 